\title{
Factors leading to tracheobronchial self-expandable metallic stent fracture
}

\author{
Fu-Tsai Chung, MD, ${ }^{*}$ Shu-Min Lin, MD, ${ }^{*}$ Hao-Cheng Chen, MD, Chun-Liang Chou, MD, Chih-Teng Yu, MD, Chien- \\ Ying Liu, MD, Chun-Hua Wang, MD, Horng-Chyuan Lin, MD, Chien-Da Huang, MD, and Han-Pin Kuo, MD, PhD
}

\begin{abstract}
Objective: This retrospective study was to determine factors that contribute to self-expandable metallic stent fracture in patients with tracheobronchial disease.

Methods: From 2001 to 2006, 139 patients (age, $62.1 \pm 15.4$ years; range, 23-87 years) with benign $(\mathrm{n}=62)$ and malignant $(n=77)$ tracheobronchial disease received 192 Ultraflex (Boston Scientific, Natick, Mass) selfexpandable metallic stents (98 in patients with benign disease and 94 in patients with malignant disease).
\end{abstract}

\begin{abstract}
Results: Seventeen fractured self-expandable metallic stents were found; the incidence was $12.2 \%(17 / 139$ patients) among patients with tracheobronchial disease. Tortuous airway (odds ratio, 4.06; 95\% confidence interval, 1.04-18.34; $P=.04$ ) independently predicted self-expandable metallic stent fracture. Most self-expandable metallic stent fractures $(64.7 \%, 11 / 17)$ were detected 500 to 1000 days after self-expandable metallic stent implantation. Clinical presentations for patients with fractured self-expandable metallic stents included dyspnea exacerbation $(70.6 \%, 12 / 17)$ and cough $(23.5 \%, 4 / 17)$.
\end{abstract}

Conclusions: Self-expandable metallic stent fracture is not uncommon in patients with tracheobronchial disease. Tortuous airway is an independent predictor for it. Although management of the fractured self-expandable metallic stent in our study was feasible and safe, self-expandable metallic stents should be restricted to a more select population.

Endoscopic airway stent implementation for airway stenosis has been an increasingly popular treatment over the last decade. Silicone stents are widely used in the maintenance of airway patency because they are easily removed and repositioned. ${ }^{1,2}$ However, their complications include migration, granulation tissue formation, and airway obstruction. Metallic stent management of tracheobronchial obstruction was introduced 10 years ago. ${ }^{3}$ Since then, self-expandable metallic stents (SEMSs) have become widely used for management of benign and malignant airway disease. They can be successfully implanted with a flexible bronchoscope during conscious sedation and local anesthesia. ${ }^{4-6}$

Although the US Food and Drug Administration announced a warning for the use of SEMSs in benign conditions, many patients received this therapeutic modality before the warning. In addition, among patients who refused surgical intervention or were not suitable for surgical intervention because of medical comorbidity or poor pulmonary function, metallic stents were reported to be safe and effective in patients with benign and malignant airways obstruction. $^{7,8}$ Unlike silicone stents, SEMSs have decreased

From the Department of Thoracic Medicine, Chang Gung Memorial Hospital, Chang Gung University, College of Medicine, Taipei, Taiwan.

* FTC and SML contributed equally to the work on this project as first authors, and none of the authors have any conflicts of interest to disclose.

Received for publication July 14, 2007; revisions received March 10, 2008; accepted for publication May 4, 2008.

Address for reprints: Han-Pin Kuo, MD, PhD, Department of Thoracic Medicine, Chang Gung Memorial Hospital, 199 Tun Hwa N Rd, Taipei, Taiwan (E-mail: q8828@ms11.hinet.net).

J Thorac Cardiovasc Surg 2008;136:1328-35

$0022-5223 / \$ 34.00$

Copyright (c) 2008 by The American Association for Thoracic Surgery doi:10.1016/j.jtcvs.2008.05.039 migration rates, greater cross-sectional airway diameters (because of thinner wall construction), better conformation with irregular airways, epithelialization within the stent that maintains mucociliary clearance, and easier placement. ${ }^{4,9}$

Although SEMSs adequately manage the narrow airway lumen caused by tracheobronchial diseases, complications include stent fracture, migration, granulation tissue formation, impaired mucociliary clearance, recurrent stent obstruction by the lumen, and increased bacterial infection. ${ }^{3,10,11}$ Therefore because of these complications, the US Food and Drug Administration warned that SEMS implantation should be considered only if the patients are not eligible for surgical intervention, rigid bronchoscopy, or silicone stent implantation. However, previous studies reported that SEMSs offer benefits in long-term treatment for benign central tracheal stenosis in a certain group of patients, ${ }^{12,13}$ but the characteristics of the patients who would benefit from SEMS implantation were not well defined.

Among the potential complications of SEMSs, fracture is of major concern because it can cause potential obstruction and wall perforation. ${ }^{14}$ Proposed causes of such fractures include repetitive coughing, esophageal compression during swallowing, ${ }^{10}$ metal fatigue, ${ }^{4}$ granulation, and shearing forces. ${ }^{15}$ However, contributory factors to fracture have not been well documented. ${ }^{10,15}$ This study explores these factors in patients with tracheobronchial disease.

\section{MATERIALS AND METHODS Patients \\ From August 2001 to September 2006, 139 patients (age $62.1 \pm 15.4$ years) underwent 192 endoscopic airway stent placements at Chang Gung Memorial Hospital, a university-affiliated hospital in Northern Taiwan.}




\section{Abbreviations and Acronyms \\ $\mathrm{CI} \quad=$ confidence interval \\ $\mathrm{IQR}=$ interquartile range \\ IRB = institutional review board \\ SEMS $=$ self-expandable metallic stent}

Ninety-eight stents were used in 62 patients with benign tracheobronchial disease, whereas 94 stents were used in 77 patients with malignancy. Silicon or other metallic stents were used by thoracic surgeons in our institution. However, most of them require rigid bronchoscopic intervention. Thoracic surgeons were routinely consulted for feasibility of surgical intervention for all the benign diseases before SEMS implantation. Of 62 patients with benign disease, 37 patients with poor pulmonary function and 19 patients with severe comorbid conditions were precluded from surgical intervention. The other 6 patients refused surgical intervention. Informed consent was obtained from all patients or their surrogates before the procedure of bronchoscopic SEMS implantation and follow-up. Methodology and patient confidentiality were approved by our institutional review board (IRB). The IRB was also asked to review the design of the project in December 2006 and approved this retrospective study in March 2007. The IRB confirmed that this study constituted an audit, which did not require patient consent to this retrospective study.

\section{Stent Implantation}

SEMSs were implanted by means of flexible bronchoscopy during conscious sedation and local anesthesia. The choice of stent length and type (with or without cover) was determined by means of previous endoscopic examination and chest computed tomographic scanning. SEMSs were implanted at the choke point, as determined by using flow-volume curve, endobronchial ultrasonography, bronchoscopy, or 3-dimensional computed tomography before and after stenting. ${ }^{16}$ Ultraflex (Boston Scientific, Natick, Mass), a tightly weaved SEMS composed entirely of a single strand of nickel-titanium alloy, was the stent of choice for this study.

\section{Assessment of Stent Condition}

After implantation of the stent, a second bronchoscopic study was performed in 48 hours. The presence of incomplete stent expansion and incomplete stent lumen expansion was recorded and evaluated in the follow-up bronchoscopic studies. In addition, each patient underwent bronchoscopic examination 1 week after implantation and then every 3 to 6 months thereafter to evaluate stent position and degradation, granulation tissue formation, and airway alignment. If dyspnea, severe coughing, increased mucus production, or other fracture symptoms occurred, additional bronchoscopic analysis was performed.

\section{Definition of Airway and SEMS Conditions}

SEMS fracture was defined as the physical breaking of the stent (Figure 1). A tortuous airway was defined as a failure to visualize either the main carina from the trachea or the second carina from either the main bronchus during bronchoscopy (Figure 2) or torsion of the airways on radiographic imaging study (Figure 3). The airway disease was defined as patients with asthma or chronic obstructive pulmonary disease. Incomplete stent lumen expansion was defined because the lumen does not complete expansion after stent implantation for more than 72 hours. Narrow stent opening was defined because the shape of the stent was not round or ovoid after implantation.

\section{Treatment for SEMS Fracture}

The treatment strategies for stent fracture include stent removal, ${ }^{17}$ another stent implantation, or observation because of no symptoms. Patients

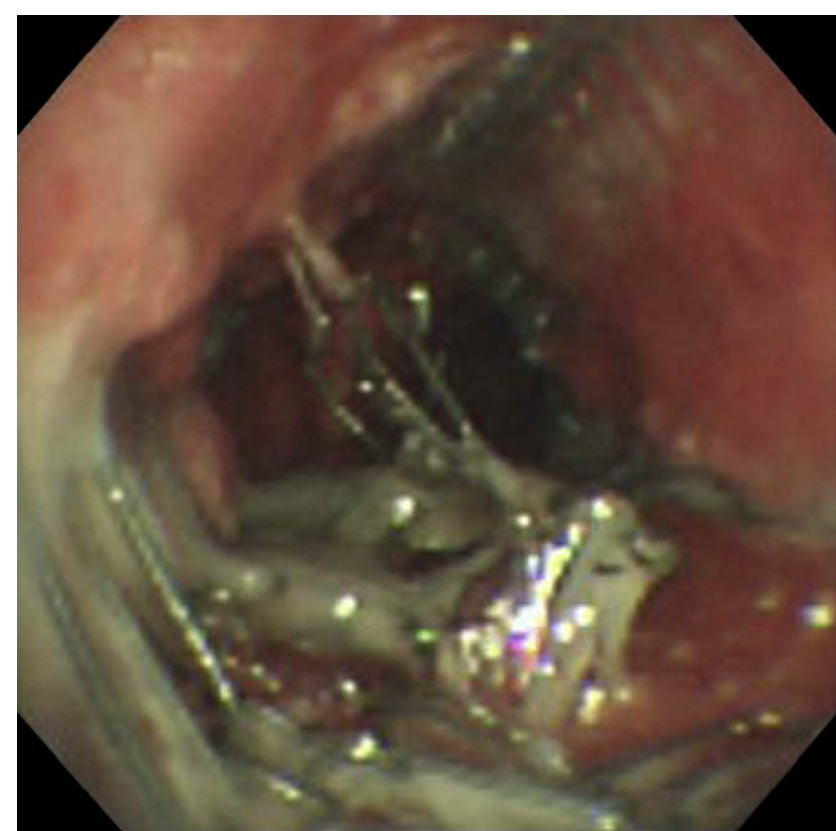

FIGURE 1. A patient with self-expandable metallic stent fracture expressed as the physical breaking of the stent.

who underwent SEMS implantation or removal were consciously sedated with midazolam during flexible bronchoscopy. Electrocautery and forceps were applied alternatively to remove the fractured stent piece by piece because SEMSs were usually tightly embedded into the epithelium of the airway mucosa. SEMS removal usually costs several days' hospitalization because it is difficult to completely remove a stent at once. Although we might spend hours removing the stent each time, neither mortality nor severe morbidity occurred. The whole hospitalization course for each stent removal was usually less than 1 week. The choice of treatment was judged individually by bronchoscopists according to the patients' clinical

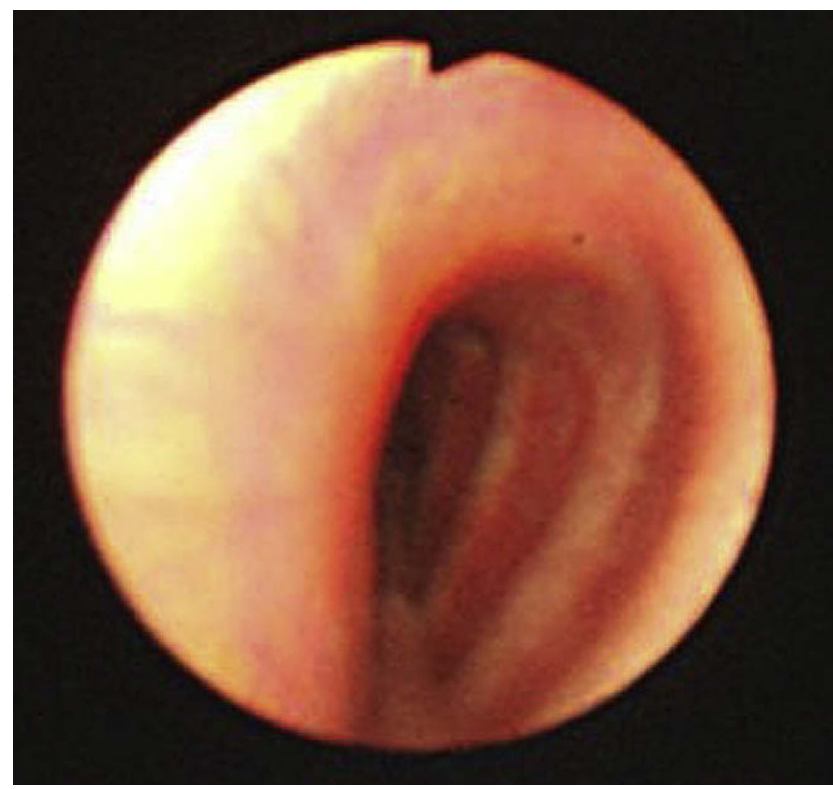

FIGURE 2. Tortuous airway expressed as failure to visualize either of the main carina from the trachea during bronchoscopic analysis. 


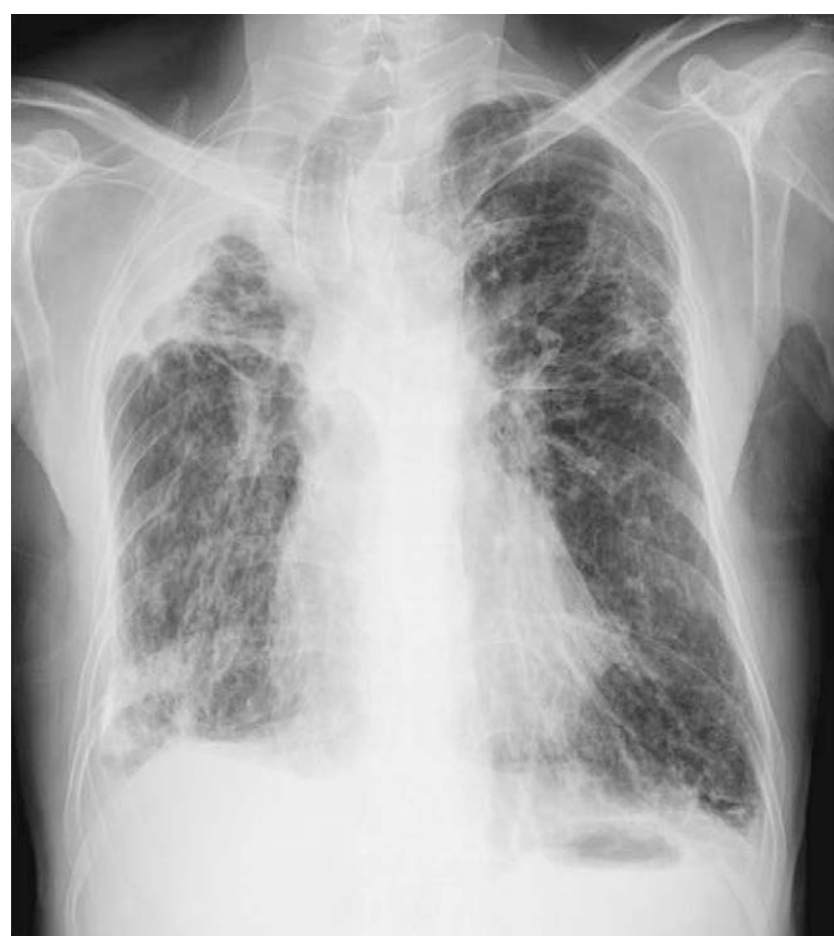

FIGURE 3. Tortuous airway on chest roentgenogram in a patient with selfexpandable metallic stent implantation.

manifestations, imaging study results, and physical status. The numbers of bronchoscopic interventions for fractured stents were listed.

\section{Statistical Analysis}

Analysis of variance and unpaired $t$ tests were used to compare stent implant duration and SEMS fracture detection with different variables, such as stent location, stent type, and fracture site. Data are expressed as medians and interquartile ranges (IQRs). Univariate analysis with the Fisher's test was primarily used for variable selection $(P<.05)$. Significant variables, such as underlying benign or malignant diseases, tortuous airway, covered stent, stent implantation for longer than 1 year, and postoperative airway condition, including granulation tissue formation, incomplete stent lumen expansion, narrowing of the stent opening, and poor airway alignment (after stent implantation), were entered into a forward logistic regression analysis to determine the net effect of each predictor while controlling the net effects of others. Odds ratios and $95 \%$ confidence intervals (CIs) were adopted to assess significant independent contributions. Time to SEMS fracture was defined as the period between the date of implantation and fracture detection. Kaplan-Meier analysis was used to determine the SEMS fracture rate curve. Fractured curves between patients, with and without pre-existing tortuous airways, were compared by using the log-rank test. All analysis was performed with SPSS software, version 10.0 (SPSS, Inc, Chicago, Ill).

\section{RESULTS}

\section{Baselines}

From 2001 to 2006, 139 patients (age, $62.1 \pm 15.4$ years; range, 23-87 years) with benign $(\mathrm{n}=62)$ and malignant $(\mathrm{n}=77)$ tracheobronchial disease received 192 Ultraflex SEMSs (98 stents in patients with benign disease and 94 stents in patients with malignant disease). The indication of SEMS implantation is presented in Table 1.
TABLE 1. Indication for self-expandable metallic stent implantation

\begin{tabular}{lrr}
\hline & $\begin{array}{c}\text { No. of } \\
\text { patients }\end{array}$ & $\begin{array}{r}\text { No. of } \\
\text { SEMSs }\end{array}$ \\
\hline Malignancy & & \\
$\quad$ Lung cancer causing airway stricture & 44 & 54 \\
Esophageal cancer & & \\
$\quad$ Airway invasion with luminal stricture & 3 & 3 \\
$\quad$ TE fistula & 24 & 31 \\
Mediastinal tumor with airway compression & 4 & 4 \\
Other malignancy causing airway stricture & 2 & 2 \\
Subtotal & 77 & 94 \\
Benign & & \\
Malacia & 26 & 56 \\
Posttuberculosis airway stricture & 8 & 8 \\
Postintubation airway stricture & 6 & 6 \\
Granuloma causing previous SEMS restenosis & 8 & 12 \\
Previous SEMS fracture & 5 & 5 \\
Airway corrosive injury with stricture & 2 & 3 \\
Mediastinitis causing airway stricture & 2 & 2 \\
Previous SEMS fatigue & 2 & 3 \\
Goiter external compression & 3 & 3 \\
Subtotal & 62 & 98 \\
Total & 139 & 192 \\
\hline$T E$ Tracheoesophageal SEMS, self-expandable metallic stent. &
\end{tabular}

The overall SEMS fracture incidence was $12.2 \%(17 / 139$ patients). However, all fractures occurred only in patients with benign lesions, with an incidence of $27.4 \%$ (17/62 patients). Treatment for stent fracture and total numbers of bronchoscopic intervention for the patients with stent fractures is shown in Table 2.

In total, of 62 patients with benign airway disease undergoing SEMS implantation, $39(62.9 \%)$ patients were still being followed up at the outpatient department, 12 $(19.4 \%)$ patients were dead, and $11(17.7 \%)$ patients were lost to follow-up. The median duration of all SEMSs in patients with benign condition was 617 days $(\mathrm{n}=62 ; \mathrm{IQR}$, 224.5-1123 days), the median duration in patients still followed up was 671 days ( $\mathrm{n}=39$; IQR, 309-1282 days), the median duration in deceased patients was 644 days ( $\mathrm{n}$ $=12$; IQR, 175.5-900.5 days), and the median duration in patients lost to follow-up was 199 days $(\mathrm{n}=11$; IQR, 65279 days).

In total, of 77 patients with malignancy undergoing SEMS implantation, $3(3.9 \%)$ patients were still followed up at the outpatient department, $67(87.0 \%)$ patients were dead, and $7(9.1 \%)$ patients were lost to follow-up. The median duration of all SEMSs in patients with malignancy was 61 days ( $\mathrm{n}=77$; IQR, 19-106 days), the median duration in patients still followed up was 315 days $(\mathrm{n}=3$; range, 238474 days), the median duration in deceased patients was 50 days ( $\mathrm{n}=67$; IQR, 17-97 days), and the median duration in patients lost to follow-up was 109 days $(\mathrm{n}=7$; IQR, 34-197 days). 
TABLE 2. Self-expandable metallic stent implantation sites, properties, indication, and times to fracture

\begin{tabular}{|c|c|c|c|c|c|c|c|c|c|}
\hline $\begin{array}{c}\text { Stent } \\
\text { no. }\end{array}$ & Location & $\begin{array}{c}\text { Indication } \\
\text { of SEMS } \\
\text { implantation }\end{array}$ & $\begin{array}{l}\text { With } \\
\text { cover }\end{array}$ & $\begin{array}{c}\text { Time to } \\
\text { fracture (d) }\end{array}$ & $\begin{array}{l}\text { Size, } \mathbf{m m} \\
(\text { diameter } \\
\times \text { length }) \\
\end{array}$ & $\begin{array}{l}\text { Symptom } \\
\text { when } \\
\text { fracture } \\
\text { detected } \\
\end{array}$ & $\begin{array}{c}\text { Fracture } \\
\text { site of stent }\end{array}$ & $\begin{array}{l}\text { Treatment for } \\
\text { stent fracture }\end{array}$ & $\begin{array}{c}\text { No. of } \\
\text { bronchoscopies }\end{array}$ \\
\hline 1 & Trachea & $\begin{array}{l}\text { Posttuberculosis } \\
\text { stenosis }\end{array}$ & + & 681 & $18 \times 80$ & Dyspnea & Proximal & $\begin{array}{l}\text { Removal and } \\
\text { restenting }\end{array}$ & 7 \\
\hline 2 & Trachea & Malacia & - & 1170 & $18 \times 60$ & Dyspnea & Intraluminal & Removal & 8 \\
\hline 3 & Trachea & $\begin{array}{l}\text { Postintubation } \\
\text { stenosis }\end{array}$ & - & 276 & $20 \times 60$ & Dyspnea & Proximal & $\begin{array}{l}\text { Removal and } \\
\text { restenting }\end{array}$ & 6 \\
\hline 4 & Trachea & Malacia & - & 617 & $20 \times 80$ & Dyspnea & Distal & Removal & 6 \\
\hline 5 & LL & Malacia & - & 733 & $10 \times 20$ & Cough & Proximal & Removal & 6 \\
\hline 6 & LM & Malacia & - & 686 & $14 \times 40$ & Cough & Intraluminal & Removal & 5 \\
\hline 7 & RL & Malacia & - & 709 & $12 \times 20$ & None & Proximal & None & 5 \\
\hline 8 & LM & $\begin{array}{l}\text { Posttuberculosis } \\
\text { stenosis }\end{array}$ & - & 522 & $14 \times 40$ & Dyspnea & Distal & $\begin{array}{l}\text { Removal and } \\
\text { restenting }\end{array}$ & 8 \\
\hline 9 & Trachea & $\begin{array}{l}\text { Postintubation } \\
\text { stenosis }\end{array}$ & + & 99 & $20 \times 40$ & Dyspnea & Intraluminal & Removal & 5 \\
\hline 10 & RIB & Malacia & - & 856 & $14 \times 40$ & Dyspnea & Proximal & $\begin{array}{l}\text { Removal and } \\
\text { restenting }\end{array}$ & 9 \\
\hline 11 & Trachea & Malacia & - & 7 & $20 \times 60$ & Dyspnea & Proximal & Removal & 3 \\
\hline 12 & Trachea & Malacia & - & 562 & $20 \times 60$ & Cough & Distal & Removal & 5 \\
\hline 13 & Trachea & $\begin{array}{l}\text { Posttuberculosis } \\
\text { stenosis }\end{array}$ & - & 905 & $18 \times 60$ & Dyspnea & Distal & Removal & 8 \\
\hline 14 & Trachea & $\begin{array}{l}\text { Posttuberculosis } \\
\text { stenosis }\end{array}$ & + & 772 & $20 \times 40$ & Dyspnea & Intraluminal & Removal & 8 \\
\hline 15 & Trachea & $\begin{array}{l}\text { Stent restenosis after } \\
\text { tissue granulation }\end{array}$ & - & 211 & $20 \times 60$ & Dyspnea & Distal & $\begin{array}{l}\text { Removal and } \\
\text { restenting }\end{array}$ & 5 \\
\hline 16 & Trachea & Postintubation stenosis & - & 750 & $20 \times 60$ & Cough & Intraluminal & Removal & 6 \\
\hline 17 & Trachea & Postintubation Stenosis & + & 1266 & $20 \times 80$ & Dyspnea & Intraluminal & Removal & 8 \\
\hline
\end{tabular}

SEMS, Self-expandable metallic stent; +, with cover; -, without cover $L L$, left lower bronchus; $L M$, left main bronchus; $R L$, right lower bronchus; $R I B$, right intermediate bronchus.

\section{Univariate and Multivariate Analysis of SEMS Fracture Factors}

SEMS properties (length and size, presence of cover, and implantation site), follow-up duration after SEMS implantation, structural factors (underlying benign or malignant diseases, airway wall dynamic collapse, and tortuous airway), postoperative airway conditions (poor airway alignment, granulation tissue formation, narrow stent opening, and incomplete stent lumen expansion), and other new postoperative symptoms were included in the univariate SEMS fracture analysis (Table 3). The dominant symptoms of stent fracture include exacerbation of dyspnea $(70.6 \%, 12 / 17)$ or cough $23.5 \%$, 4/17). One symptom-free fracture was found during routine bronchoscopy.

For multivariate analysis, only underlying tortuous airway (odds ratio, $4.33 ; 95 \% \mathrm{CI}, 1.09-18.3 ; P=.04$ ) acted as an independent predictor of stent fracture (Table 4). Postoperative granulation tissue formation $(\mathrm{n}=26,36.6 \% ; P<$ $.01)$, incomplete stent lumen expansion ( $\mathrm{n}=27,38 \% ; P<$ $.01)$, narrow stent opening, $(\mathrm{n}=23,32.4 \% ; P<.01)$, and poor airway alignment $(\mathrm{n}=35,49.3 \% ; P<.01)$ were all more prevalent in patients with tortuous airways $(\mathrm{n}=71)$ than in those without $(\mathrm{n}=121 ; 14.9 \%, 12.4 \%, 7.4 \%$, and $5.8 \%$, respectively; Table 5). Cover stent, underlying benign disease, duration of more than 1 year after stent implantation, and presence of new postoperative symptoms, such as dyspnea exacerbation, were not significantly different between these groups (Table 5).

\section{Time to SEMS Fracture in Patients With Tracheobronchial Disease}

Overall SEMS fracture incidence in this group varied with time. The fracture rate was $2.1 \%(4 / 192)$ in the first year, $9.4 \%(6 / 64)$ in the second year, $13.9 \%(5 / 36)$ in the third year, $11.1 \%(2 / 18)$ in the fourth year, and nil $(0 / 11)$ in the fifth year (Figure 4). Most fractures $(64.7 \%, 11 / 17)$ were detected 500 to 1000 days after implantation (Table 2). The incidence increased rapidly after the second year for patients with tortuous airways (Figures 5 and 6). Time to fracture detection was not affected by stent location (trachea versus bronchus: median, 649 days [IQR, 243.5-838.5 days; $\mathrm{n}=$ 12] vs 709 days [IQR, 604-794.5 days; $\mathrm{n}=5$ ]; $P=.63$ ), type (covered vs uncovered: median, 726.5 days [IQR, 390-1019 days; $\mathrm{n}=4$ ] vs 686 days [IQR, 399-803 days; $\mathrm{n}=13] ; P=.664$ ), or fracture site (proximal, distal, and intraluminal: median, 695 days [IQR, 141.5-794.5 days; $\mathrm{n}=6$ ], 
TABLE 3. Univariate analysis of factors associated with self-expandable metallic stent fracture in patients with tracheobronchial disease $(\mathbf{n}=192)$

\begin{tabular}{|c|c|c|c|c|}
\hline Factors & Fracture incidence $(\%)$ & Odds ratio & $95 \%$ CI & $P$ value \\
\hline \multicolumn{5}{|l|}{ SEMS implantation site } \\
\hline Trachea $(\mathrm{n}=116)$ & $12(10.3)$ & 1.64 & $0.55-4.85$ & .37 \\
\hline Bronchi $(\mathrm{n}=76)$ & $5(6.6)$ & & & \\
\hline \multicolumn{5}{|l|}{ SEMS characteristics } \\
\hline \multicolumn{5}{|l|}{ Length of SEMS in trachea $(n=116)$} \\
\hline$>6 \mathrm{~cm}(\mathrm{n}=40)$ & $3(7.5)$ & 1.66 & $0.42-6.50$ & .47 \\
\hline$<6 \mathrm{~cm}(\mathrm{n}=76)$ & $9(11.8)$ & & & \\
\hline \multicolumn{5}{|l|}{ Length of SEMS in bronchi $(n=76)$} \\
\hline$>4 \mathrm{~cm}(\mathrm{n}=66)$ & $3(4.4)$ & 5.25 & $0.76-36.35$ & .07 \\
\hline$<4 \mathrm{~cm}(\mathrm{n}=10)$ & $2(20.0)$ & & & \\
\hline \multicolumn{5}{|l|}{ Size of SEMS in trachea $(n=116)$} \\
\hline$>18 \mathrm{~mm}(\mathrm{n}=62)$ & $9(14.5)$ & 2.89 & $0.74-11.27$ & .11 \\
\hline$<18 \mathrm{~mm}(\mathrm{n}=54)$ & $3(5.6)$ & & & \\
\hline \multicolumn{5}{|l|}{ Size of SEMS in bronchi $(\mathrm{n}=76)$} \\
\hline$>14 m m(n=61)$ & $3(4.9)$ & 2.97 & $0.45-19.65$ & .24 \\
\hline$<14 \mathrm{~mm}(\mathrm{n}=15)$ & $2(13.3)$ & & & \\
\hline Covered $(\mathrm{n}=120)$ & $4(3.3)$ & 6.39 & $2.0-20.46$ & .0005 \\
\hline Uncovered $(\mathrm{n}=72)$ & $13(18.1)$ & & & \\
\hline \multicolumn{5}{|l|}{ Follow-up duration after SEMS implantation } \\
\hline $1 \mathrm{y}(\mathrm{n}=62)$ & $13(21.0)$ & 8.36 & $2.60-26.89$ & $<.0001$ \\
\hline$<1$ y $(\mathrm{n}=130)$ & $4(3.1)$ & & & \\
\hline \multicolumn{5}{|l|}{ Underlying diseases } \\
\hline Benign disease $(\mathrm{n}=98)$ & $17(17.3)$ & 40.6 & $2.40-685.9$ & $<.0001$ \\
\hline Malignant disease $(\mathrm{n}=94)$ & $0(0)$ & & & \\
\hline \multicolumn{5}{|l|}{ Airway condition before SEMS implantation } \\
\hline \multicolumn{5}{|l|}{ Airway wall } \\
\hline Dynamic collapse $(\mathrm{n}=73)$ & $8(11.0)$ & 1.50 & $0.55-4.09$ & .42 \\
\hline Fixed airway lesion $(\mathrm{n}=119)$ & $9(7.6)$ & & & \\
\hline \multicolumn{5}{|l|}{ Airway lumen } \\
\hline Tortuous airway $(\mathrm{n}=71)$ & $12(16.9)$ & 4.72 & $1.59-14.03$ & .003 \\
\hline Nontortuous airway $(\mathrm{n}=121)$ & $5(4.1)$ & & & \\
\hline \multicolumn{5}{|l|}{ Airway condition after SEMS implantation } \\
\hline Poor airway alignment $(n=42)$ & $7(16.7)$ & 2.80 & $0.99-7.88$ & .04 \\
\hline Narrow stent opening $(\mathrm{n}=32)$ & $8(25.0)$ & 5.59 & $1.97-15.91$ & .0004 \\
\hline Granulation tissue formation $(n=44)$ & $11(25.0)$ & 7.89 & $2.72-22.88$ & $<.0001$ \\
\hline Incomplete stent lumen expansion $(n=42)$ & $7(16.7)$ & 2.80 & $0.99-7.88$ & .04 \\
\hline \multicolumn{5}{|l|}{ New symptoms after SEMS implantation } \\
\hline Exacerbated postoperative dyspnea $(n=86)$ & $12(14.0)$ & 3.28 & $1.11-9.70$ & .03 \\
\hline Exacerbated postoperative coughing $(\mathrm{n}=65)$ & $4(6.2)$ & 1.74 & $0.54-5.57$ & .35 \\
\hline
\end{tabular}

CI, Confidence interval; SEMS, self-expandable metallic stent.

562 days [IQR, 366.5-761 days, $\mathrm{n}=5$ ], and 761 days [IQR, 392.5-1218 days, $\mathrm{n}=6$ ]; $P=.414$; Table 6). According to log-rank test analysis (Figure 6), fracture incidence was higher in patients with tortuous airways (62.6\% vs $18.6 \%$; hazard ratio, 5.59; 95\% CI, 2.06-14.82; $P=.0007$ ).

\section{DISCUSSION}

Despite similar numbers of SEMSs implanted in patients with malignancy, no stent fracture was detected in this group, and this is likely because of the short survival time of these patients, which precludes development of stent fractures. Patients with malignancy-induced central airway obstruction only survived a median of 61 days $(n=77$; IQR,
19-106 days) after stent implantation. The median time to stent fracture is 686 days (IQR, 399-814 days). In univariate analysis duration of stent implantation of more than 1 year (odds ratio, 8.36; $P<.0001$ ) contributes to stent fracture, although the net effect disappears in multivariate analysis. Underlying benign disease (odds ratio, 40.6; $P<.0001$ ) also contributes to stent fracture in univariate analysis. It was not able to analyze in multivariate analysis for all fractured SEMS only found in patients with benign disease. A short lifespan in patients with malignancy might not be long enough for the development of stent fracture. These results demonstrate that tracheobronchial stent fracture is not uncommon in benign airway disease, and therefore other 
TABLE 4. Multivariate analysis of factors associated with selfexpandable metallic stent fracture in patients with tracheobronchial disease $(n=192)$

\begin{tabular}{lclc}
\hline \multicolumn{1}{c}{ Factors } & Odds ratio & \multicolumn{1}{c}{$\mathbf{9 5 \%}$ CI } & $\boldsymbol{P}$ value \\
\hline Cover stent & 0.06 & $0.18-3.79$ & .80 \\
More than 1 y after stent implantation & 1.18 & $0.51-10.52$ & .28 \\
Underlying benign disease & None & None & None \\
Underlying tortuous airway & 4.06 & $1.04-18.34$ & .04 \\
Poor postoperative airway alignment & 0.08 & $0.15-4.20$ & .78 \\
Narrow stent opening & 0.56 & $0.28-17.47$ & .46 \\
Granulation tissue formation & 1.36 & $0.52-12.98$ & 0.24 \\
Incomplete stent lumen expansion & 0.04 & $0.13-12.18$ & .84 \\
Exacerbated postoperative dyspnea & 1.11 & $0.56-7.09$ & .29 \\
\hline
\end{tabular}

$C I$, Confidence interval.

alternative therapeutic strategies should be evaluated before SEMS implantation in patients with benign disease.

Although many possible causes of stent fracture have been proposed, such as repetitive coughing, compression from the esophagus during swallowing, ${ }^{10}$ metal fatigue, ${ }^{4}$ granulation, and shearing force,${ }^{15}$ the mechanism for stent fracture is still undetermined. This study demonstrates that stent length and size, along with sites of implantation or fracture, are not related to fracture. Structural factors (tortuous airway and underlying benign disease), covered stent, postoperative airway conditions (poor alignment, incomplete stent lumen expansion, granulation tissue formation, and narrow stent opening), duration of stent implantation of more than 1 year, and new postoperative symptoms (dyspnea) are related to stent fracture. However, underlying tortuous airway has proved to be the only independent predictor for stent fracture. Logistic regression analysis revealed a 5fold increase in fracture risk for patients with tortuous airways when compared with those without airway tortuosity. The patients with tortuous airways also had a higher incidence of granulation tissue formation, incomplete stent

TABLE 5. Postoperative airway conditions in patients with or without tortuous airways

\begin{tabular}{lccc}
\hline & $\begin{array}{c}\text { Tortuous } \\
\text { airway } \\
(\mathbf{n}=\mathbf{7 1}), \\
\mathbf{n}(\%)\end{array}$ & $\begin{array}{c}\text { Nontortuous } \\
\text { airway } \\
(\mathbf{n}=\mathbf{1 2 1}), \\
\mathbf{n}(\%)\end{array}$ & $\begin{array}{c}\boldsymbol{P} \\
\text { value* }\end{array}$ \\
\hline Contributing factors & $42(59.2)$ & $78(64.5)$ & .46 \\
More than 1 y after stent & $24(33.8)$ & $38(31.4)$ & .73 \\
$\quad$ implantation & & & \\
Underlying benign disease & $32(45.1)$ & $66(54.5)$ & .2 \\
Poor airway alignment & $35(49.3)$ & $7(5.8)$ & $<.0001$ \\
Narrow stent opening & $23(32.4)$ & $9(7.4)$ & $<.0001$ \\
Granulation tissue formation & $26(36.6)$ & $18(14.9)$ & .0005 \\
Incomplete stent lumen & $27(38.0)$ & $15(12.4)$ & $<.0001$ \\
$\quad$ expansion & & & \\
Newly developed dyspnea & $30(42.3)$ & $56(46.3)$ & .59 \\
\hline *Fisher's exact test. & & &
\end{tabular}

*Fisher's exact test.

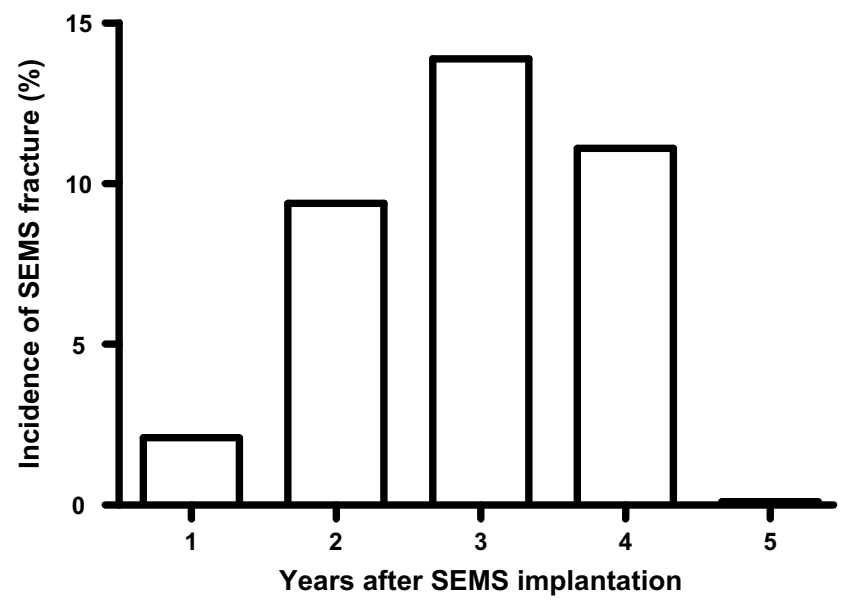

FIGURE 4. Yearly overall self-expandable metallic stent (SEMS) fracture incidence in patients with tracheobronchial disease.

lumen expansion, poor airway alignment, and narrow stent opening when compared with those without airway tortuosity. Therefore SEMS implantation should be avoided in patients with benign central airway lesions and tortuous airways.

The results suggest that stents implanted in tortuous airways cannot maintain their ideal architecture and alignment. Increased shearing forces on these stents, with subsequent granulation tissue formation, might lead to fracture. Postoperative granulation tissue formation, stent expansion failure, poor airway alignment, and narrow airway lumen all might stem from a tortuous airway; they might not be independent causes of stent fracture.

Notwithstanding the low case number in the fifth year, overall SEMS fracture incidence increased with time. There was no significant change in the incidence of SEMS fracture with time in patients with nontortuous airways. Incidence increased abruptly after 2 years in patients with tortuous

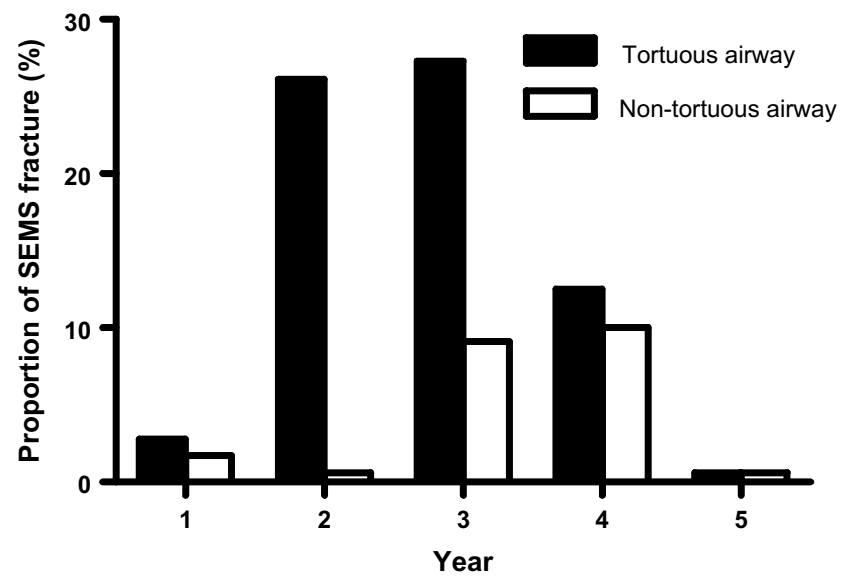

FIGURE 5. Yearly self-expandable metallic stent (SEMS) fracture incidence in patients with or without tortuous airways. 


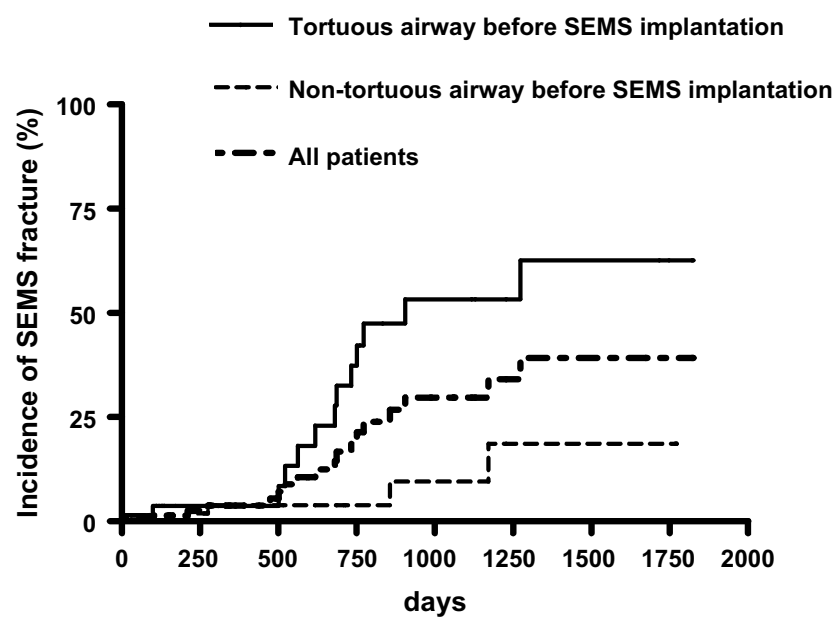

FIGURE 6. Logistic regression analysis of cumulative self-expandable metallic stent (SEMS) fracture incidence in patients with or without tortuous airways $(62.6 \%$ vs $18.6 \%$; hazard ratio, $5.59 ; 95 \%$ confidence interval, $2.06-14.82 ; P=.0007)$.

airways. No stent properties significantly affected the time to fracture. Most SEMS fractures were detected after dyspnea or cough exacerbation; however, there was 1 patient with SEMS fracture who was totally asymptomatic. Therefore regular bronchoscopic examination is mandatory after SEMS implantation, particularly for patients with tortuous airways after the first year.

Nevertheless, the high incidence of stent fracture in patients with benign airway diseases after a short-term follow-up precludes SEMS implantation from replacing surgical correction as a therapeutic intervention in patients suitable for an operation. Surgical treatment in patients with such benign airway diseases should be the first choice, unless patients were unsuitable for surgical intervention because of poor lung function, comorbidities, or surgical refusal. Still, the balance between clinical benefit and a risk of stent fracture should be cautiously considered for SEMS implantation in these patients. In patients with tortuous airways, narrow stent opening, granulations, incomplete stent expansion, benign airway diseases, covered stent implantation, or duration of stent implantation of more than 1 year, regular radiologic or bronchoscopic examination and close monitoring of exacerbation or new development of dyspnea or coughing after SEMS implantation is mandatory.

Surgical treatment in patients with such benign airway diseases should be the first choice. If patients were unsuitable for surgical intervention because of poor lung function, comorbidities, or surgical refusal, SEMS implantation during medical bronchoscopy would be tried if no other treatment were available. However, these patients must be closely monitored for development of new symptoms, and radiologic or bronchoscopic examination should be arranged.
TABLE 6. Variables associated with time to self-expandable metallic stent fracture

\begin{tabular}{|c|c|c|}
\hline Variables & $\begin{array}{c}\text { Time to SEMS fracture, } \\
\text { d (median [IQR]) }\end{array}$ & $\begin{array}{c}P \\
\text { value }\end{array}$ \\
\hline Total fractured stent count $(n=17)$ & $686(399-814)$ & \\
\hline \multicolumn{3}{|l|}{ Location } \\
\hline Trachea $(\mathrm{n}=12)$ & $649(243.5-838.5)$ & .630 \\
\hline Bronchi $(\mathrm{n}=5)$ & $709(604-794.5)$ & \\
\hline Left-sided bronchi $(\mathrm{n}=3)$ & 686 & .265 \\
\hline Right-sided bronchi $(\mathrm{n}=2)$ & 782.5 & \\
\hline \multicolumn{3}{|l|}{ Type of stent } \\
\hline Covered $(n=4)$ & $726.5(390-1019)$ & .664 \\
\hline Uncovered $(\mathrm{n}=13)$ & $686(399-803)$ & \\
\hline \multicolumn{3}{|l|}{ Site of fracture } \\
\hline Proximal $(n=6)$ & $695(141.5-794.5)$ & .414 \\
\hline Distal $(\mathrm{n}=5)$ & $562(366.5-761)$ & \\
\hline Intraluminal $(n=6)$ & $761(392.5-1218)$ & \\
\hline
\end{tabular}

SEMS, Self-expandable metallic stent; $I Q R$, interquartile range.

The treatment for SEMS fracture is feasible in our study. There were higher total numbers of bronchoscopic interventions after SEMS implantation in patients with stent fractures than in those without (mean $\pm \mathrm{SD}, 6.35 \pm 1.62$ vs $3.03 \pm 2.5 ; P<.0001$, not shown on tables). No mortality or sever morbidity developed during and after bronchoscopic intervention for a fractured stent in our study.

In summary, SEMS fracture is not uncommon in patients with benign tracheobronchial disease, and a tortuous airway is an independent predictor for it. SEMS fracture incidence increases dramatically 2 years after implantation. A prospective study with regular radiologic or bronchoscopic examination is warranted to evaluate the true incidence of stent fracture, even in the absence of symptoms. In conclusion, given the high rate of stent failure among patients with benign disease, metal stents should be restricted to a highly selected population rather than all patients with benign disease to specifically avoid situations in which long-term use of the stent is anticipated.

\section{References}

1. Martinez-Ballarin JI, Diaz-Jimenez JP, Castro MJ, Moya JA. Silicone stents in the management of benign tracheobronchial stenoses. Tolerance and early results in 63 patients. Chest. 1996;109:626-9.

2. Wood DE, Liu YH, Vallieres E, Karmy-Jones R, Mulligan MS. Airway stenting for malignant and benign tracheobronchial stenosis. Ann Thorac Surg. 2003;76: 167-74.

3. Noppen M, Meysman M, Claes I, D'Haese J, Vincken W. Screw-thread vs Dumon endoprosthesis in the management of tracheal stenosis. Chest. 1999; 115:532-5.

4. Aggarwal A, Dasgupta A, Mehta AC. Metalloptysis expulsion of wire stent fragments. Chest. 1999;115:1484-5. 
5. Madden BP, Datta S, Charokopos N. Experience with Ultraflex expandable metallic stents in the management of endobronchial pathology. Ann Thorac Surg. 2002;73:938-44.

6. Saad CP, Murthy S, Krizmanich G, Mehta AC. Self-expandable metallic airway stents and flexible bronchoscopy: long-term outcomes analysis. Chest. 2003;124: 1993-9.

7. Madden BP, Loke TK, Sheth AC. Do expandable metallic airway stents have a role in the management of patients with benign tracheobronchial disease? Ann Thorac Surg. 2006;82:274-8.

8. Husain SA, Finch D, Ahmed M, Morgan A, Hetzel MR. Long-term follow-up of Ultraflex metallic stents in benign and malignant central airway obstruction. Ann Thorac Surg. 2007;83:1251-6.

9. Nashef SA, Dromer C, Velly JF, Labrousse L, Couraud L. Expanding wire stents in benign tracheobronchial disease: indications and complications. Ann Thorac Surg. 1992;54:937-40.

10. Zakaluzny SA, Lane JD, Mair EA. Complications of tracheobronchial airway stents. Otolaryngol Head Neck Surg. 2003;128:478-88.
11. Gaissert HA, Grillo HC, Wright CD, Donahue DM, Wain JC, Mathisen DJ Complication of benign tracheobronchial strictures by self-expanding metal stents. J Thorac Cardiovasc Surg. 2003;126:744-7.

12. Ducic Y, Khalafi RS. Use of endoscopically placed expandable nitinol tracheal stents in the treatment of tracheal stenosis. Laryngoscope. 1999;109:1130-3.

13. Vergnon JM, Costes F, Bayon MC, Emonot A. Efficacy of tracheal and bronchial stent placement on respiratory functional tests. Chest. 1995;107:741-6.

14. Rousseau H, Dahan M, Lauque D, Carre P, Didier A, Bilbao I, et al. Self-expandable prostheses in the tracheo-bronchial tree. Radiology. 1993;188:199-203.

15. Burningham AR, Wax MK, Andersen PE, Everts EC, Cohen JI. Metallic tracheal stents: complications associated with long-term use in the upper airway. Ann Otol Rhinol Laryngol. 2002;111:285-90.

16. Miyazawa T, Miyazu Y, Iwamoto Y, Ishida A, Kanoh K, Sumiyoshi H, et al Stenting at the flow-limiting segment in tracheobronchial stenosis due to lung cancer. Am J Respir Crit Care Med. 2004;169:1096-102.

17. Lunn W, Feller-Kopman D, Wahidi M, Ashiku S, Thurer R, Ernst A. Endoscopic removal of metallic airway stents. Chest. 2005;127:2106-12. 